\title{
Evidence- based medicine performance among health care providers in Iranian hospitals: A nationwide survey
}

\author{
Farbod Ebadifard Azar ${ }^{1}$, Aziz Rezapour ${ }^{2}$, Haleh Mousavi Isfahani ${ }^{3}$, Saber Azami-Aghdash ${ }^{4}$, \\ Khalil Kalavani ${ }^{5}$, Feridun Mahmoudi ${ }^{1 *}$
}

Received: 14 Nov 2016

Published: 12 Dec 2017

\begin{abstract}
Background: Evidence- Based Medicine (EBM) refers to the ability and skill in the use and integration of the best evidence obtained from repeatable bias-free clinical trials with the patients' preferences and conditions. Considering this fact that few large-scale studies have been done in this field in Iran, the present study aimed at comprehensively reviewing the status of EBM performance among health care providers in Iranian hospitals.

Methods: This cross-sectional study was conducted during 2014 and 2015. Study participants consisted of 2800 health care providers (physicians, nurses, midwives, and paramedical personnel) in active hospitals in Iran. Data collection tool was a self-made questionnaire. Content validity of the questionnaire was improved by comments of 10 experts. The reliability of the questionnaire was assessed using test-retest method $(\alpha=0.85)$.

Results: The results revealed that only $12.7 \%$ and $15.8 \%$ of the participants were highly familiar with EBM databases and terminologies, respectively. Most participants believed that EBM-related workshops and practical involvement in EBM-related programs and activities can have a more effect on the improvement of EBM performance. Most participants had a positive view of the EBM. About $47 \%$ of the participants reported that their EBM knowledge and skills is high. Among the demographic variables, there were only significant relationships between work experience and attitude, gender and attitudes, and between knowledge and skills $(p<0.05)$.

Conclusion: According to the results of the present study, it seems that holding EBM-related workshops and practical participation in EBP-related programs and activities as well as improving facilities such as manpower, equipment, and access can have a significant effect on improving EBM- related activities.
\end{abstract}

Keywords: Evidence- based medicine, Health care providers, Attitudes, Knowledge, Skills

Copyright@ Iran University of Medical Sciences

Cite this article as: Ebadifard Azar F, Rezapour A, Mousavi Isfahani H, Azami-Aghdash S, Kalavani Kh, Mahmoudi F. Evidence- based medicine performance among health care providers in Iranian hospitals: A nationwide survey. Med J Islam Repub Iran. 2017 (12 Dec);31:77. https://doi.org/10.14196/mjiri.31.77

\section{Introduction}

In recent years, increase in elderly population, emergence of new technologies and knowledge, a rising expectations of costumers of health care services and society, and changing professional attitudes and expectations have

Corresponding author: Feridun Mahmoudi, mahmoudi39@yahoo.com

1. Health Management and Economics Research Center, Iran University of Medical Sciences, Tehran, Iran.

2. Department of Health Economics, School of Health Management and Information Sciences, Iran University of Medical Sciences, Tehran, Iran.

3. School of Health Management and Information Sciences, Iran University of Medical Sciences, Tehran, Iran.

4. Iranian Center of Excellence in Health Management, Tabriz University of Medical Sciences, Tabriz, Iran.

5. Department of Health Management, School of Health, Qazvin University of Medical Sciences, Qazvin, Iran. increased the provision of health care services (1); hence, health care providers have found trends toward evidencebased medicine (EBM) $(2,3)$.

EBM was considered for the first time after the French

$\uparrow$ What is "already known" in this topic:

Previous studies in Iran have demonstrated that knowledge, attitude, and performance level of different groups of health care providers about EBM is low.

$\rightarrow$ What this article adds:

Only $12.7 \%$ of the participants were highly familiar with EBM databases. Only $15.8 \%$ were highly familiar with EBM terms. Most participants believed that EBM-related workshops and practical involvement in EBM-related programs and activities could have a great impact on the improvement of EBM performance. About $47 \%$ of the participants reported that their knowledge and skills on EBM was high and very high. 
Revolution in Paris, and some of its earlier roots were found in Chinese medicine. EBM modern term was proposed for the first time by a Canadian epidemiologist named Gordon Guyatt et al. from McMaster University, Canada in 1992; then, it was adopted by the Cochrane Collaboration (4).

EBM refers to the ability and skill in the use and integration of the best evidence obtained from repeatable biasfree clinical trials with the patient's preferences and conditions $(5,6)$. The most common definition of EBM has been provided by Dr. David Sackett. EBM refers to correct and judicious use of the current best evidence in decision-making about patients. This means integrating individual clinical expertise with the best available external clinical evidence obtained from targeted research (4).

Concurrent with the use of EBM in various fields, many studies have been conducted worldwide on knowledge, attitudes, practices (7-9), barriers and facilitators (10-18), understanding of the performance-based evidence concept (19-25), and other aspects. There are 5 basic steps in implementing EBM: (1) defining the problem, which means to develop a relevant and searchable clinical question according to the form of the disease; (2) searching for resources and databases to find relevant clinical papers; (3) critically evaluating information; (4) obtaining evidence in validity and using information and evidence missing for the intended patients; and (5) evaluating the usefulness and effectiveness of the use of such evidence (26).

EBM has been considered in many areas of medical sciences in Iran during the past few years $(27,28)$. Previous studies in Iran have demonstrated that knowledge, attitude, and performance level of different groups of health care providers about EBM is low $(29,30)$. Thus, considering the importance and position of EBM and the fact that there are few sufficient large-scale studies in this field in Iran, the present study aimed at comprehensively reviewing the status of EBM performance among health care providers in Iranian hospitals.

\section{Methods}

This was a cross-sectional study, which was conducted in the second 6 months of 2014 and the first 6 months of 2015.

Participants were all health care providers (physicians, nurses, midwives and paramedical personnel) in active hospitals in Iran. To select the hospitals, 7 provinces were initially selected randomly from among the provinces, which are as follow: Qazvin, Golestan, SistanBaluchestan, South Khorasan, East Azarbaijan, Khuzestan, and Kerman. Then, 5 hospitals were randomly selected in the provincial capital in each province. Next, 80 staffs were selected from among the health care providers and included into the study.

In this study, exclusion criteria were as follow: Less than 1 year of work experience; employment in administrative and management units of hospitals; being busy with studying and working in hospitals; working in military hospitals; and not willing to participate in the study. Data collection tool was a multi-part self-made questionnaire that covered all goals of the study. This question- naire was designed based on the review of the literature, and its content validity was improved based on the judgment of 10 experts in the EBM field. To assess the internal consistency of the questionnaire, constructive interitem correlation was assessed using Cronbach's alpha. The questionnaire reliability was assessed using test-retest, with at least 50 people $(\alpha=0.85)$.

The questionnaire consisted of 2 main parts: the first part included demographic information (6 questions); the second part consisted of the main questions that respectively included an introduction to each EBM database (6 databases), familiarity with any of EBM terms (11 terms), feeling the need to improve EBM performance activities (4 activities), questions on knowledge and skills $(n=10)$, and questions on attitude $(\mathrm{n}=9)$.

Sample size was calculated using a random sampling method by the predicted value equal to 0.5 , accuracy of 0.02 , and confidence level of 2 . Finally, sample size was calculated to be 2500 . Also, to prevent a decrease in the number of participants, the researchers added $10 \%$ to this population, and the final sample size was calculated to be 2800. To collect data, interviewers were used from selected provinces because they were familiar with the local language and customs of those provinces. To create consistency and common language among the interviewers, a workshop was held for them, and a pilot study with a sample size of at least 50 people was performed to ensure inter-rater reliability.

Ethical considerations in this study included the following: permission from the ethics committee of Iran University of Medical Sciences; coordination with the relevant authorities, hospitals, and universities; obtaining informed consent from participants; and preserving appropriate confidentiality of the information of the participants.

Descriptive statistics (mean \pm standard deviation), frequency distribution (number and percentage), independent samples $t$ test and one- way ANOVA were used for data analysis using SPSS.16 software package. A p-value less than $5 \%$ was considered statistically significant.

\section{Results}

From among 2800 questionnaires distributed, a total of 1524 questionnaires were completed and collected (response rate of $54.4 \%$ ). The mean $\pm \mathrm{SD}$ age of the participants was $31.2 \pm 7.2$ years. Most participants were females $(51.6 \%)$. Nurses accounted for $53.8 \%$ of the participants. Most of the participants had a bachelor's degree (66.1\%) and were working in the public sector (67.3\%). Participants' demographic characteristics are presented in Table 1.

About $39 \%$ of the participants had low familiarity with the EBM databases, and only $12.7 \%$ were highly familiar with EBM databases (Table 2).

The results revealed that $39.5 \%$ of the participants had low familiarity with EBM terminology and only $15.8 \%$ were highly familiar with EBM terms (Table 3).

Most participants believed that EBM-related workshops and practical involvement in EBM-related programs and activities could have a great impact on the improvement of EBM performance. However, a small percentage of them 


\begin{tabular}{lll} 
Table 1. Demographic characteristics of the participants & \\
\hline Variable & Variable level & Number (\%) \\
\hline Gender & Male & $648(42.5)$ \\
& Female & $786(51.6)$ \\
Job & Unknown & $90(5.9)$ \\
& Physician & $330(21.7)$ \\
& Nurse & $888(53.8)$ \\
Midwife & $150(9.8)$ \\
& Radiology technician & $78(5.1)$ \\
& Laboratory technician & $66(4.3)$ \\
Other & $6(0.4)$ \\
Education & Unknown & $6(0.4)$ \\
& BS & $1008(66.1)$ \\
& Masters & $108(7.1)$ \\
& Ph.D. & $36(2.4)$ \\
& Professional doctorate & $66(4.3)$ \\
& Specialist & $102(6.7)$ \\
Work experience & Subspecialty & $36(2.4)$ \\
& 1 to 5 years & $324(21.1)$ \\
& 6 to 10 years & $240(15.7)$ \\
& 11 to 15 & $120(8)$ \\
& More than 15 years & $90(6)$ \\
Workplace & Unknown & $750(49.2)$ \\
& Public & $1026(67.3)$ \\
& Private & $144(9.4)$ \\
& Social security & $132(8.7)$ \\
& Public and private & $180(11.8)$ \\
& Public and social security & $30(2)$ \\
& Private and social Security & $12(0.8)$ \\
\hline & & \\
& & \\
& &
\end{tabular}

believed that EBM-related journal clubs could have a positive impact on the improvement of EBM-related activities (Table 4).

Most participants had a positive view towards EBM so that about $97 \%$ of them believed EBM will lead to better clinical outcomes. Despite the positive attitude of the participants, about $75 \%$ acknowledged that EBM limits discretion of health care providers, and about $91 \%$ believed it is difficult to implement EBM due to the heavy workload and the large number of patients (Table 5).

Table 2. Familiarity with the EBM databases among particpants $(\mathrm{N}=1524)$

\begin{tabular}{|c|c|c|c|c|}
\hline Database & Low & Average & High & Unknow \\
\hline Bandolier (published in Oxford) & $468(30.7)^{*}$ & $654(42.5)$ & $276(18.1)$ & $126(8.3)$ \\
\hline Evidence-Based Medicine(BMJ publishing group) & $510(33.5)$ & $660(43.3)$ & $246(16.1)$ & $108(7.1)$ \\
\hline Effective Health Care Bulletins & $570(37.4)$ & $648(42.5)$ & $186(12.2)$ & $120(7.9)$ \\
\hline Cochrane Database of Systematic Reviews & $564(37)$ & $684(44.9)$ & $162(10.6)$ & $114(7.5)$ \\
\hline Database of Abstracts of Reviews of Effectiveness & $750(49.2)$ & $504(33.1)$ & $150(9.8)$ & $120(7.9)$ \\
\hline Evidence-Based Purchasing & $708(46.5)$ & $522(34.4)$ & $144(9.4)$ & $150(9.8)$ \\
\hline Total $(\%)$ & 39 & 40.2 & 12.7 & 8 \\
\hline
\end{tabular}

*Number $(\%)$

Table 3. Familiarity with the EBM terminology among particpants $(\mathrm{N}=1524)$

\begin{tabular}{|c|c|c|c|c|}
\hline EBM Terminology & Low & Average & High & Unknow \\
\hline Absolute risk & * 540(35.4) & $552(36.2)$ & $324(21.3)$ & $108(7.1)$ \\
\hline Relative risk & $486(31.9)$ & $690(45.3)$ & $264(17.3)$ & $84(5.5)$ \\
\hline Systematic review & $510(33.5)$ & $660(43.3)$ & $276(18.1)$ & $78(5.1)$ \\
\hline Odds Ratio & $666(43.7)$ & $480(31.5)$ & $270(17.7)$ & $108(7.1)$ \\
\hline Likelihood ratio (LR) & $690(45.3)$ & $474(31.1)$ & $240(15.7)$ & $120(7.9)$ \\
\hline Meta-analysis & $594(39)$ & $606(39.8)$ & $210(13.8)$ & $114(7.5)$ \\
\hline Clinical effectiveness & $588(38.6)$ & $636(41.7)$ & $228(15)$ & $72(4.7)$ \\
\hline Number needed to treat & $474(31.1)$ & $648(42.5)$ & $282(18.5)$ & $120(7.9)$ \\
\hline Confidence interval (CI) & $660(43.3)$ & $540(35.4)$ & $186(12.2)$ & $138(9.1)$ \\
\hline Heterogeneity & $708(46.5)$ & $540(35.4)$ & $174(11.4)$ & $102(6.7)$ \\
\hline P-Value & $714(46.9)$ & $456(29.9)$ & $204(13.4)$ & $150(9.8)$ \\
\hline Total (\%) & 39.5 & 37.4 & 15.8 & 7.1 \\
\hline
\end{tabular}

Table 4. Participants belief about EBM improving activities $(\mathrm{N}=1524)$

\begin{tabular}{|c|c|c|c|c|}
\hline EBM improves activities & Unknow & High & Average & Low \\
\hline EBM-related workshops & $312(20.5)^{*}$ & $660(43.3)$ & $462(30.3)$ & $90(5.9)$ \\
\hline Access to EBM-related resource & $276(18.1)$ & $690(45.3)$ & $426(28)$ & $132(8.6)$ \\
\hline EBM-related journal clubs & $348(22.8)$ & $678(44.5)$ & $330(21.7)$ & $168(11)$ \\
\hline practical participation in EBM-related programs and activities & $234(15.4)$ & $672(44.1)$ & $486(31.9)$ & $132(8.6)$ \\
\hline Total $(\%)$ & 19.2 & 44.3 & 27.975 & 8.575 \\
\hline
\end{tabular}

*Number $(\%)$ 


\begin{tabular}{|c|c|c|c|c|c|c|c|c|c|}
\hline \multicolumn{2}{|l|}{ Databases } & \multicolumn{2}{|c|}{$\begin{array}{l}\text { Totally } \\
\text { agree }\end{array}$} & \multicolumn{2}{|c|}{$\begin{array}{l}\text { Somewhat } \\
\text { agree }\end{array}$} & No idea & Disagree & $\begin{array}{c}\text { Totally } \\
\text { disagree }\end{array}$ & Unknown \\
\hline \multicolumn{2}{|l|}{ EBM will lead to better clinical outcomes. } & \multicolumn{2}{|c|}{$714(46.9)^{*}$} & \multicolumn{2}{|c|}{$756(49.6)$} & $6(0.4)$ & $18(1.2)$ & 0 & $30(2)$ \\
\hline \multicolumn{2}{|l|}{ EBM reduces the cost of the health system. } & \multicolumn{2}{|c|}{$606(39.8)$} & \multicolumn{2}{|c|}{$816(53.5)$} & 0 & $72(4.7)$ & 0 & $30(2)$ \\
\hline \multicolumn{2}{|c|}{ EBM is essential for all health service providers. } & \multicolumn{2}{|c|}{$528(34.6)$} & \multicolumn{2}{|c|}{$858(56.3)$} & $6(0.4)$ & $102(6.7)$ & 0 & $30(2)$ \\
\hline \multicolumn{2}{|c|}{ There is no obstacle in applying EBM for all patients. } & \multicolumn{2}{|c|}{$408(26.8)$} & \multicolumn{2}{|c|}{$732(48)$} & $18(1.2)$ & $318(20.9)$ & $18(1.2)$ & $30(2)$ \\
\hline \multicolumn{2}{|c|}{ EBM does not consider patient's preferences and values. } & \multicolumn{2}{|c|}{$318(20.9)$} & \multicolumn{2}{|c|}{$642(42.1)$} & $18(1.2)$ & $510(33.5)$ & $6(0.4)$ & $30(2)$ \\
\hline \multirow{2}{*}{\multicolumn{2}{|c|}{$\begin{array}{l}\text { EBM limits discretion of health care providers. } \\
\text { It is difficult to implement EBM due to heavy workload } \\
\text { and high number of patients. }\end{array}$}} & \multicolumn{2}{|c|}{$348(22.8)$} & \multicolumn{2}{|c|}{654 (52.9) } & 0 & $468(30.7)$ & $24(1.6)$ & $30(2)$ \\
\hline & & \multicolumn{2}{|c|}{$618(40.6)$} & \multicolumn{2}{|c|}{$762(50)$} & $12(0.8)$ & $90(5.9)$ & $12(0.8)$ & $30(2)$ \\
\hline \multirow{2}{*}{\multicolumn{2}{|c|}{$\begin{array}{l}\text { EBM is a waste of time. } \\
\text { Despite the large volume of scientific papers in the field } \\
\text { of medicine, a very small amount of this information } \\
\text { can be used in EBM. }\end{array}$}} & \multicolumn{2}{|c|}{288 (18.9) } & \multicolumn{2}{|c|}{$696(45.7)$} & 0 & $450(29.5)$ & $60(3.9)$ & $30(2)$ \\
\hline & & \multicolumn{2}{|c|}{$516(33.9)$} & \multicolumn{2}{|c|}{$762(50)$} & $12(0.8)$ & $180(11.8)$ & 24 (1.6) & $30(2)$ \\
\hline \multicolumn{10}{|c|}{ *Number $(\%)$} \\
\hline \multicolumn{10}{|c|}{ Table 6. Participants' level of knowledge and skills on EBM(N =1524) } \\
\hline Knowledge and skills on EBM & \multicolumn{2}{|c|}{ Very high } & \multicolumn{2}{|c|}{ High } & & erage & Low & Very low & Unknown \\
\hline $\begin{array}{l}\text { Converting your work-related issues and prob- } \\
\text { lems into a specific research question }\end{array}$ & 336 & $(22)^{*}$ & 53 & $(35)$ & & $(32.3)$ & $90(5.9)$ & $36(2.4)$ & $36(2.4)$ \\
\hline $\begin{array}{l}\text { Searching databases to extract needed articles } \\
\text { and information }\end{array}$ & 318 & $(20.9)$ & 510 & $(33.5)$ & & $(33.1)$ & $114(7.5)$ & $36(2.4)$ & $42(2.8)$ \\
\hline Ability to design a study & 192 & $(12.6)$ & 53 & $(35)$ & & $(30.3)$ & $234(15.4)$ & $48(3.1)$ & $54(3.5)$ \\
\hline Meeting sample size for your study & 234 & $(15.4)$ & 36 & $(24)$ & & $(33.9)$ & $270(17.7)$ & $96(6.3)$ & $42(2.8)$ \\
\hline Performing statistical tests & 192 & $(12.6)$ & 330 & $(21.7)$ & & $(36.2)$ & $300(19.7)$ & $114(7.5)$ & $36(2.4)$ \\
\hline Writing an article & 204 & $(13.4)$ & 36 & $(24)$ & & $(33.5)$ & $294(19.3)$ & $108(7.1)$ & $42(2.8)$ \\
\hline Assessment of biases in articles & 174 & (11.4) & 39 & $(26)$ & & $(31.9)$ & $300(19.7)$ & $132(8.7)$ & $36(2.4)$ \\
\hline Critical assessment of articles & & $(13)$ & 39 & $(26)$ & & $(32.7)$ & $318(20.9)$ & $78(5.1)$ & $36(2.4)$ \\
\hline Using research findings in your field & 252 & $(16.5)$ & 59 & $(39)$ & & $(30.3)$ & $138(9.1)$ & $36(2.4)$ & $42(2.8)$ \\
\hline $\begin{array}{l}\text { Transferring and exchanging information with } \\
\text { your colleagues }\end{array}$ & 360 & $(23.6)$ & 618 & $(40.6)$ & & $(28.7)$ & $72(4.7)$ & 0 & $36(2.4)$ \\
\hline Total $(\%)$ & & 6.1 & & 1.2 & & 2.1 & 13.9 & 4.5 & 2.6 \\
\hline
\end{tabular}

About $47 \%$ of the participants reported that their knowledge and skills on EBM was high and very high. Also, about $32 \%$ and $18 \%$ of them reported that their level of knowledge and skills was average and low, or very low, respectively (Table 6).

Among the demographic variables, there were signification relationships between work experience and attitude, gender and attitude, and between knowledge and skills $(\mathrm{p}<0.05)$.

\section{Discussion}

Results of the present study revealed that $39 \%$ of the participants had low familiarity with the EBM databases and only $12.7 \%$ were highly familiar with these databases. Of the participants, $39.5 \%$ had low familiarity with EBM terms and only $15.8 \%$ were highly familiar with these terms. Most participants believed that EBM-related workshops and practical participation in EBM-related programs and activities could have a positive impact on the improvement of EBM-related activities. Most participants had a positive view towards the EBM so that about $97 \%$ of the participants believed EBM will lead to better clinical outcomes. Participants' knowledge and skills on EBM is relatively high so that about $47 \%$ of them reported that level of their knowledge and skills on EBM is very high and high.

The results revealed that health service providers have relatively low knowledge of terms and proprietary databases of EBM. The lowest familiarity and understanding relate to heterogeneity, confidence interval, and odds ratio, which is largely consistent with the results of previous studies (31-33). In the current study, participants' awareness of some of the terms such as absolute risk and systematic review was high compared to other terms, and this might have been due to the literal meanings of these terms because they seem to have simple meanings, but they have complicated meanings and concepts statistically and methodologically that need to be investigated further. In general, the results of awareness and understanding of EBM specific terms indicate that the health care providers' level of knowledge about statistical and methodological terms is less compared with practical terms in the workplace. Hence, it is recommended to train the health care providers about statistical and methodological issues to empower them to use and implement EBM. According to previous studies in Iran, a systematic training program increased the participants' skills on $\operatorname{EBM}(34,35)$ thus, there is a need for careful theoretical and practical planning in different aspects to increase individuals' familiarity with EBM including participation in workshops and training courses, journal clubs and the grand rounds, conferences, seminars, and meetings. Therefore, it seems essential to develop an appropriate and comprehensive training curriculum in the field of EBM in universities of medical sciences in Iran in the future.

The present study revealed that health care providers' perspective about EBM in Iran is relatively positive. The result of Parvin et al.'s study reflected the attitude of most nurses towards evidence-based nursing such as Egerod and Hansen's research results $(36,37)$, while in Koehn \& Lehman, study, participants had a moderate attitude towards evidence-based cares and there was a significant 
difference between attitudes of undergraduate and graduate nurses (38). In Aghahoseini study, most nurses had apathetic attitude towards evidence-based nursing, and there was a significant relationship between nurses' attitudes and age (39). In a study, Lai et al. reported that physicians had a positive attitude, but nurses and health care providers had a negative attitude towards evidence-based cares (40). A positive attitude towards evidence-based care can pave the ground for starting and raising awareness of evidence- based practice, and it seems that information exchange and interaction among all health care providers in health care centers can provide a suitable ground for the application of EBM. Most of the participants believed that EBM-related workshops and practical participation EBM-related programs and activities can have a great effect on the improvement of EBM-related activities, which is consistent with most previous studies abroad $(5,41-52)$. Thus, according to the results of this study and almost identical results in other studies, fulfilling the foregoing can have a large impact on improving the quality of EBM activities in Iran. The interesting point was that most participants in the present study acknowledged that journal clubs cannot have a large impact on improving the quality of EBM activities, which may be due to low quality and type of journal clubs, which are held in the form of lectures. In this regard, Shokouhi et al. (2012) found that the design of evidence-based journal club, compared to the current Journal clubs, has a better effect on assistants' consent (53). Thus, it seems that the effectiveness of journal clubs in the performance of EBM is enhanced by changing the manner of holding these clubs and improving their effectiveness using the available evidence (54).

Although the present study has been conducted on a large scale and with the large number of participants from different health care providers and included many dimensions of EBM, the main limitation of this study was the large number of lack of responses from the participants, especially physicians. Also, despite trained interviewers and a pilot study to achieve consistency between the participants, due to varying conditions of the hospitals in different cities, the researchers were worried about using the same procedure for data collection and data entry in different cities.

\section{Conclusion}

Results of the present study revealed that individuals' knowledge of EBM databases and terms was relatively low, while they had relatively high knowledge and skills. Health care providers' attitude towards EBM in Iran's hospitals was positive. According to the results, it seems that holding EBM-related workshops and practical participation in EBM-related programs and activities as well as improving facilities such as manpower, equipment, space, and access can have a significant effect on improving EBM- related activities.

\section{Acknowledgments \\ This study was supported by Iran University of Medical}

Sciences. Grant no 93-04-16-255

\section{Conflict of Interests}

The authors declare that they have no competing interests.

\section{References}

1. Melnyk B, Overholt E. Evidence-Based Practice in Nursing \& Healthcare. 1 ed. Philadelphia: Lippincott Williams \& Wilkins; 2005.

2. Martis R, Ho J, Crowther C. Survey of knowledge and perception on the access to evidence-based practice and clinical practice change among maternal and infant health practitioners in South East Asia. BMJ Pregnancy Childbirth. 2008;5(8):34.

3. Dalrymple PW, Lehmann HP, Roderer NK, Streiff MB. Applying evidence in practice: a qualitative case study of the factors affecting residents' decisions. Health Informatics J. 2010;16(3):177-88.

4. Melnyk B, Overholt E. Evidence-Based Practice in Nursing \& Healthcare. 1 ed. Philadelphia: Lippincott Williams \& Wilkins; 2005.

5. Chandramohan A, Jacob KS, Shyamkumar NK, Gibikote S. Evidence-based practice in radiology: Knowledge, attitude and perceived barriers to practice among residents in radiology. Eur J Radiol. 2013;82(5):894-7.

6. Lyons C, Brown T, Tseng MH, Casey J, McDonald R. Evidencebased practice and research utilisation: perceived research knowledge, attitudes, practices and barriers among Australian paediatric occupational therapists. Aust Occup Ther J. 2011;58(3):17886.

7. Ghojazadeh M, Hajebrahimi S, Azami-Aghdash S, Pournaghi Azar F, Keshavarz M, Naghavi-Behzad M, et al. Medical students' attitudes on and experiences with evidence-based medicine: a qualitative study. Journal of evaluation in clinical practice. 2014;20(6):779-785.

8. Adeodu A, Agius R, Madan I. Attitudes and barriers to evidencebased guidelines among UK occupational physicians. Occup Med (Lond). 2009;59(8):586-92.

9. Anuradha C, Jacob KS, Shyamkumar NK, Sridhar G. Evidencebased practice in radiology: Knowledge, attitude and perceived barriers to practice among residents in radiology. Eur J Radiol. 2013;82(5):894-7.

10.Bolter R, Kuhlein T, Ose D, Gotz K, Freund T, Szecsenyi J, et al. Barriers to evidence-based medicine encountered among GPs - an issue based on misunderstanding? A qualitative study in the general practice setting. Z Evid Fortbild Qual Gesundhwes. 2010;104(89):661-6.

11.Jacobs JA, Dodson EA, Baker EA, Deshpande AD, Brownson RC. Barriers to evidence-based decision making in public health: a national survey of chronic disease practitioners. Public Health Rep. 2010;125(5):736-42.

12. Madoff RD, Winter DC, Nicholls JR, Rasmussen PC. Barrier between scientific evidence and clinical practice. Ugeskrift for laeger. 2011;173(14):1033.

13. McKillop A, Crisp J, Walsh K. Barriers and enablers to implementation of a New Zealand-wide guideline for assessment and management of cardiovascular risk in primary health care: a template analysis. Worldviews Evid Based Nurs.. 2012;9(3):159-71.

14. Rezazadeh E, Hachesu PR, Rezapoor A, Alireza K. Evidence-based medicine: going beyond improving care provider viewpoints, using and challenges upcoming. J Evid Based Med. 2014;7(1):26-31.

15.Rapp CA, Etzel-Wise D, Marty D, Coffman M, Carlson L, Asher $\mathrm{D}$, et al. Barriers to evidence-based practice implementation: results of a qualitative study. Community Ment Health J. 2010;46(2):1128.

16. Taba P, Rosenthal M, Habicht J, Tarien H, Mathiesen M, Hill S, et al. Barriers and facilitators to the implementation of clinical practice guidelines: a cross-sectional survey among physicians in Estonia. BMC Health Serv Res. 2012;12:455.

17. Van't Leven N, Graff MJ, Kaijen M, de Swart BJ, Olde Rikkert MG, Vernooij-Dassen MJ. Barriers to and facilitators for the use of an evidence-based occupational therapy guideline for older people with dementia and their carers. Int $J$ Geriatr Psychiatry. 2012;27(7):742-8. 
18. Sadeghi-Bazargani H, Tabrizi JS, Azami-Aghdash S. Barriers to evidence-based medicine: a systematic review. Journal of evaluation in clinical practice. 2014;20(6):793-802.

19. Betz ME, Barber CW, Miller M. Firearm restriction as suicide prevention: variation in belief and practice among providers in an urban emergency department. Inj Prev. 2010;16(4):278-81.

20.Halcon LL, Chlan LL, Kreitzer MJ, Leonard BJ. Complementary therapies and healing practices: faculty/student beliefs and attitudes and the implications for nursing education. J Prof Nurs. 2003;19(6):387-97.

21. Heiwe S, Kajermo KN, Tyni-Lenne R, Guidetti S, Samuelsson M, Andersson IL, et al. Evidence-based practice: attitudes, knowledge and behaviour among allied health care professionals. Int $\mathrm{J}$ Qual Health Care. 2011;23(2):198-209.

22.Jette DU, Bacon K, Batty C, Carlson M, Ferland A, Hemingway $\mathrm{RD}$, et al. Evidence-based practice: beliefs, attitudes, knowledge, and behaviors of physical therapists. Phys Ther. 2003;83(9):786805 .

23.Larios SE, Wright S, Jernstrom A, Lebron D, Sorensen JL. Evidence-based practices, attitudes, and beliefs in substance abuse treatment programs serving American Indians and AlaskaNatives: a qualitative study. J Psychoactive Drugs. 2011;43(4):355-9.

24. Tariman JD, Berry DL, Cochrane B, Doorenbos A, Schepp KG. Physician, patient, and contextual factors affecting treatment decisions in older adults with cancer and models of decisionmaking: a literature review. Oncol Nurs Forum.. 2012;39(1):E70-83.

25. Thorsteinsson HS. Icelandic Nurses' Beliefs, Skills, and Resources Associated with Evidence-Based Practice and Related Factors: A National Survey. Worldviews Evid Based Nurs. 2013;10(2):116-26.

26. Madhavji A, Araujo EA, Kim KB, Buschang PH. Attitudes, awareness, and barriers toward evidence-based practice in orthodontics. Am J Orthod Dentofacial Orthop. 2011;140(3):309-16.e2

27.Ghojazadeh M, Azami-Aghdash S, Pournaghi Azar F, Fardid M, Mohseni M, Tahamtani T. A systematic review on barriers, facilities, knowledge and attitude toward evidence-based medicine in Iran. J Anal Res Clin Med 2015; 3(1): 1-11

28. Mozafarpour S, SadeghizadehA, Kabiri P, Taheri H, Attaei M, Khalighinezhad N. Evidence-based medical practice in developing countries: the case study of Iran. J Eval Clin Pract. 2011;17(4):6516

29. Ahmadi-Abhari S, Soltani A, Hosseinpanah F. Knowledge and attitudes of trainee physicians regarding evidence-based medicine: a questionnaire survey in Tehran, Iran. J Eval Clin Pract. 2008;14(5):775-9

30. Tahmasebi fard N, Nakhshab M, Shafiei M. A primary study on the attitude, knowledge and behaviorof speech and language pathologists toward evidence-based practice. Res Rehab Sci. 2012;8(1):65-76. [In Persian].

31. Ghojazadeh M, Azami-Aghdash S, Naghavi-Behzad M. Evidencebased care in Iran: A Systematic Review. J Birjand Univ Med Sci.. 2014; 21 (2) :142-159

32.O'Donnell CA. Attitudes and knowledge of primary care professionals towards evidence-based practice: a postal survey. J Eval Clin Pract. 2004;10(2):197-205.

33. Amin M, Saunders JA, Fenton JE. Pilot study of the knowledge and attitude towards evidence based medicine of otolaryngology higher surgical trainees. Clinical Otolaryngology. 2007;32(2):133-5.

34. Taheri H, Mirmohammad Sadeghi M, Adibi I, Ashourioun V, Sadeghizadeh A, Adibi P. The effect of an evidence based medicine workshop on undergraduate medical students' skills in applying EBM. Iran J Med Edu. 2006;6(2):71-8.

35. Rafiei S, Ghajarzadeh M, Habibollahi P, Fayazbakhsh A. The effect of introducing evidence based medicine on critical appraisal skills of medical students. Iran J Med Edu. 2008;8(1):149-53.

36. Thomas EJ, Sexton JB, Helmreich RL. Discrepant attitudes about teamwork among critical care nurses and physicians. Crit Care Med. 2003;31(3):956-9.

37.Egerod I, Hansen GM. Evidence-based practice among Danish cardiac nurses: a national survey. J Adv Nurs. 2005;51(5):465-73.

38. Koehn ML, Lehman K. Nurses' perceptions of evidence-based nursing practice. J Adv Nurs. 2008;62(2):209-15.

39. Aghahoseini S. Nurses 'knowledge and attitude in evidence-based nursing in kashan university of medical sciences' teaching hospitals. Tabriz Nurs Midw J. 2011;6(2):45-54.

40.LaiNM, Teng CL, Lee ML. The place and barriers of evidence based practice: knowledge and perceptions of medical, nursing and allied health practitioners in malaysia. BMC Res Notes. 2010;3(1):1.

41. Omer T. Research utilization in a multicultural nursing setting in Saudi Arabia: barriers and facilitators. J Nurs Res. 2012;20(1):6673.

42.Parahoo K. Barriers to, and facilitators of, research utilization among nurses in Northern Ireland. J Adv Nurs. 2000;31(1):89-98.

43. Glacken M, Chaney D. Perceived barriers and facilitators to implementing research findings in the Irish practice setting. J Clin Nurs. 2004;13(6):731-40.

44. Risahmawati RR, Emura SS, Nishi TT, Koizumi SS. Japanese Resident Physicians' Attitudes, knowledge, and Perceived Barriers on the Practice of Evidence Based Medicine: a Survey. BMC Res Notes.. 2011;4:374-.

45. Goderis G, Borgermans L, Mathieu C, Van den Broeke C, Hannes $\mathrm{K}$, Heyrman J, et al. Barriers and facilitators toevidence based care of type 2 diabetes patients: experiences of general practitioners participating to a quality improvement program. Implement Sci. 2009 $22 ; 4: 41$

46. Vasse E, Vernooij-Dassen M. Barriers and facilitators to implement evidence based psychosocial care in dementia: A focus group approach using multinational and multidisciplinary expert groups. Int Psychogeriatr. 2011;23:S370-S1.

47. Davis EM, Jamison P, Brumley R, Enguidanos S. Barriers and facilitators to replicating an evidence-based palliative care model. Home Health Care Serv Q. 2006;25(1-2):149-65.

48. Leasure AR, Stirlen J, Thompson C. Barriers and facilitators to the use of evidence-based best practices. Dimens Crit Care Nurs. 2008;27(2):74-82

49. Asadoorian J, Hearson B, Satyanarayana S, Ursel J. Evidence-based practice in healthcare: an exploratory cross-discipline comparison of enhancers and barriers. J Healthc Qual. 2010;32(3):15-22.

50. Meline T, Paradiso T. Evidence-based practice in schools: Evaluating research and reducing barriers. Lang Speech Hear Serv Sch. 2003;34(4):273-83.

51. Worrall LE, Bennett S. Evidence-based practice: Barriers and facilitators for speech-language pathologists. J Med Speech Lang Pathol. 2001;9(2): 208-220.

52. Bartelt TC, Ziebert C, Sawin KJ, Malin S, Nugent M, Simpson P. Evidence-Based Practice: Perceptions, Skills, and Activities of Pediatric Health Care Professionals. J Pediatr Nurs. 2011;26(2):11421.

53. Shokouhi G, Ghojazadeh M, Sattarnezhad N. Organizing Evidence Based Medicine (EBM) Journal Clubs in Department of Neurosurgery, Tabriz University of Medical Sciences. Int J Health Sci (Qassim). 2012;6(1):59-62.

54.Deenadayalan Y, Grimmer-Somers K, Prior M, Kumar S. How to run an effective journal club: a systematic review. J Eval Clin Pract. 2008;14(5):898-911. 